\title{
Description of field trench configuration and processing and interpretation of ground penetrating radar's data
}

\author{
Sun Tianzhu ${ }^{1}$, Shen Chen $^{1}$, Feng Guoqi ${ }^{1}$, Zhang Bolin ${ }^{1}$, Tao Jianbo ${ }^{1}$, \\ Yan Baiquan ${ }^{1}$ \\ ${ }^{1}$ Earth Sciences institute, Northeast Petroleum University, Daqing City, Heilongjiang Province, 163318
}

\begin{abstract}
In recent years, ground penetrating radar (GPR) has been widely used as a technical means to understand the characteristics of subsurface geological deposition. However, there has not been any ground penetrating radar to recognize the internal configuration of the dam. The aim of this study is to form a composite dam with a point bar stack. Firstly, the highest resolution frequency of GPR is selected, and then the data are taken in the study area. And eliminate the influence of various factors on data volume. On the basis of the previous work, the location, the formation mechanism and the spatial distribution of the composite dam are determined by measuring the location of the point dam overlap and the dip angle, inclination and thickness of the lateral accretion.
\end{abstract}

Keyword: Ground penetrating radar; Field trench; the meandering river point bar; Point dam configuration.

Preface:

The main contents of this test include the detailed description and interpretation of the field configuration element, the processing and interpretation of GPR data ${ }^{[1]}$. Test period from January 15, 2015 to April 15, 2015. Detailed test items, the number of test samples and the corresponding parameters are required to see the following table:

Table 1 test items

\begin{tabular}{|c|c|c|c|}
\hline Table 1 test items & Test item & Parameters obtained & Sample quantity \\
\hline 1 & $\begin{array}{c}\text { Fine description and interpretation of the } \\
\text { configuration elements of the field trench }\end{array}$ & $\begin{array}{c}\text { Configuration unit superposition } \\
\text { relation }\end{array}$ & 4 \\
\hline 2 & $\begin{array}{c}\text { Ground penetrating radar data processing and } \\
\text { interpretation }\end{array}$ & $\begin{array}{c}\text { The scale of lateral accretion in } \\
\text { point dam }\end{array}$ & 80 \\
\hline
\end{tabular}

\subsection{Target body 1}

\section{Target area ground penetrating radar survey scheme}

Target 1 latitude and longitude latitude 49 degrees 19'0-52, 117 degrees east longitude 46'55-72, distance north Hulun Lake $9-5 \mathrm{~km}$, the altitude is about $546 \mathrm{~m}$, and the lake Hulun altitude difference is $6-7 \mathrm{~m}$ (540M). From the surface morphology observation (Figure 1), the target body 1 is a composite dam formed by the superposition of point dams. The development process, formation mechanism and spatial distribution of the composite dam are determined by measuring the location of the joint of the dam and the inclination, inclination and thickness of the lateral accretion. In order to measure the contact characteristics of point bar superimposed parts and different point bar lateral accretion body designed as shown in Figure 37 lines) (Figure 1), in which the main line 26 (red), spacing of $10 \mathrm{~m}, 20 \mathrm{~m}$; tie line 12 (yellow), pitch $30 \mathrm{~m}^{[2]}$.

Point bar $1115 \mathrm{~m}$ span and 2 span preset point bar $110 \mathrm{~m}$, spacing of line A1-A13 10m product features with the abandoned channel in the direction of measurement in the dam two vertical side, side layer and lateral accretion body angle, inclination, thickness, point bar 1 and 2 cut point bar stack contact model and relationship and product direction; response parameter measurement, the abandoned channel side laminated in the vertical side line S4-S12 measuring distance of 30m, and the A1-A13 line from the closure effect ${ }^{[3]}$. The measurement of line $\mathrm{C} 1-\mathrm{C} 8$, the 4 of the span of $70 \mathrm{~m}$ of the dam at the point of $80 \mathrm{~m}-\mathrm{span}$ of $10 \mathrm{~m}$, and the measurement of the lateral inclination angle, inclination and thickness of the aggregate, and the measurement and closure of S1-S7. In order to obtain the most intuitive geological data, this study designed a trench sampling point near the abandoned river channel of A7 near point 1. The distance is near the abandoned channel, which can GPR measurement results from calibration function, also can be directly observed underground lateral accretion bodies form even two dam cut between the overlapping features. Because of the most direct understanding of the underground geological conditions, this study is designed to explore the location of the slot for the center of the CMP to measure the position of the speed of the electromagnetic wave in the region to get the speed of underground transmission. 


\subsection{Target body 2}

Target 2 latitude and longitude latitude 49 degrees 19'30-06, longitude 46'40-40 ", located on the north shore of Hulun Lake, distance north Hulun Lake $9-5 \mathrm{~km}$, the altitude is about $545 \mathrm{~m}$, and the lake Hulun altitude difference is $4-5 \mathrm{~m}(540 \mathrm{M})$. The target for 2 of three lateral direction and different complex asymmetric composite point point dam dam formation (Figure 1), different parts of the measurement of the lateral accretion body angle, inclination, thickness, clear target dam development process, formation mechanism and spatial distribution.

In the target body 2, the point dam 1 span 90m, point dam span of $100 \mathrm{~m}$, point dam span $3100 \mathrm{~m}$. In order to find out the relationship between the 3 small dams, the study of the 44 different directions in the distance of 10m line (Figure 1), in order to point dam in 1,2, and the relationship between the internal and do a quantitative system. Point dam 1:A1-A5, A14-A20, spacing 10M, measurement of lateral accretion dip, dip, thickness, B16-B20, spacing 10m, measurement of lateral accretion inclination, inclination, thickness. Point bar 2:A5-A13, spacing $10 \mathrm{~m}$, measurement of lateral accretion dip angle, inclination, thickness, B1-B12, spacing $10 \mathrm{~m}$, measurement of lateral accretion inclination, inclination, thickness. Point dam 3:A1-A5, A14-A20, spacing $10 \mathrm{~m}$, measurement of lateral accretion angle, direction, thickness, B1-B16, spacing 10M, measurement of lateral accretion inclination, inclination, thickness.
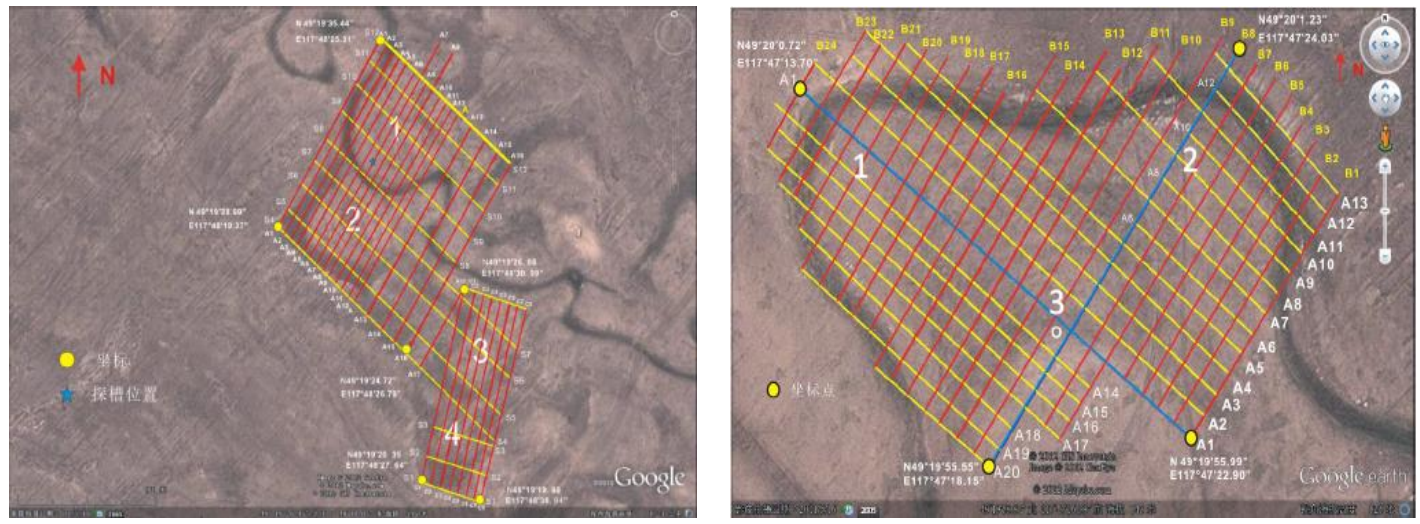

Fig. 1 measurement scheme design of target body 1 and target body 2

\section{GPR data processing}

According to the design scheme, the depth and resolution of 4 kinds of antennas with different frequencies of $35 \mathrm{MHz}, 40 \mathrm{MHz}, 80 \mathrm{MHz}$ and $100 \mathrm{MHz}$ were measured on the $\mathrm{A} 7$ line of the target body in the area of the underground geological exploration in this area. And analysis of test results that due to multiple effects of surface weeds and loose soil resulting from the surface, causing $8 \mathrm{~m}$ below the ground penetrating radar measurement data is invalid, so the frequency of less than $80 \mathrm{MHz}$ (depth of $8 \sim 9 \mathrm{~m}$ ) of the antenna in the area can show the advantages of detection (the main frequency is smaller, more deep exploration). Therefore, in the process of measurement considering the vertical resolution and the detection depth, choose based on frequency of $80 \mathrm{MHz}$ antenna, the overall characteristics of detection point bar, point bar, laminated side cut overlapping parts, and in the online test with the same $100 \mathrm{MHz}$ antenna covered again measurements to precisely characterize shallow lateral accretion characteristics of interface configuration unit ${ }^{[4]}$.

Based on the above analysis, the ground penetrating radar is investigated by using $80 \mathrm{MHz}$ and $100 \mathrm{MHz}$ frequency antennas, and a total of 37 ground penetrating radar targets in the target area are collected for $16313 \mathrm{~m}$. On the $80 \mathrm{MHz}$ and $100 \mathrm{MHz}$ antenna measurements, the lateral migration patterns formed by the migration of the channel are observed. In order to eliminate the influence of topographic relief on the ground penetrating radar measurement in the later stage, the GPS coordinates and elevation of the lowest point and the horizontal position on both sides of the river are recorded at the location of the obvious fluctuation. Due to the close distance between the target 2 and the target body, the geological environment is similar to that of the, and the $80 \mathrm{MHz}$ antenna is directly used to measure the target 2 according to the designed detection scheme. The target area 2 collected a total of 44 GPR profiles, with a total length of $4379 \mathrm{~m}^{[5]}$.

In the process of ground penetrating radar data acquisition, the factors such as surface fluctuation will affect the data. In order to eliminate these effects, the research data on the admission of zero distance, normalized surface normalization, time correction, dynamic balance, automatic gain predictive disconsolation, $\mathrm{Q}$, offset compensation, static correction of a series of processing (Figure 2) 

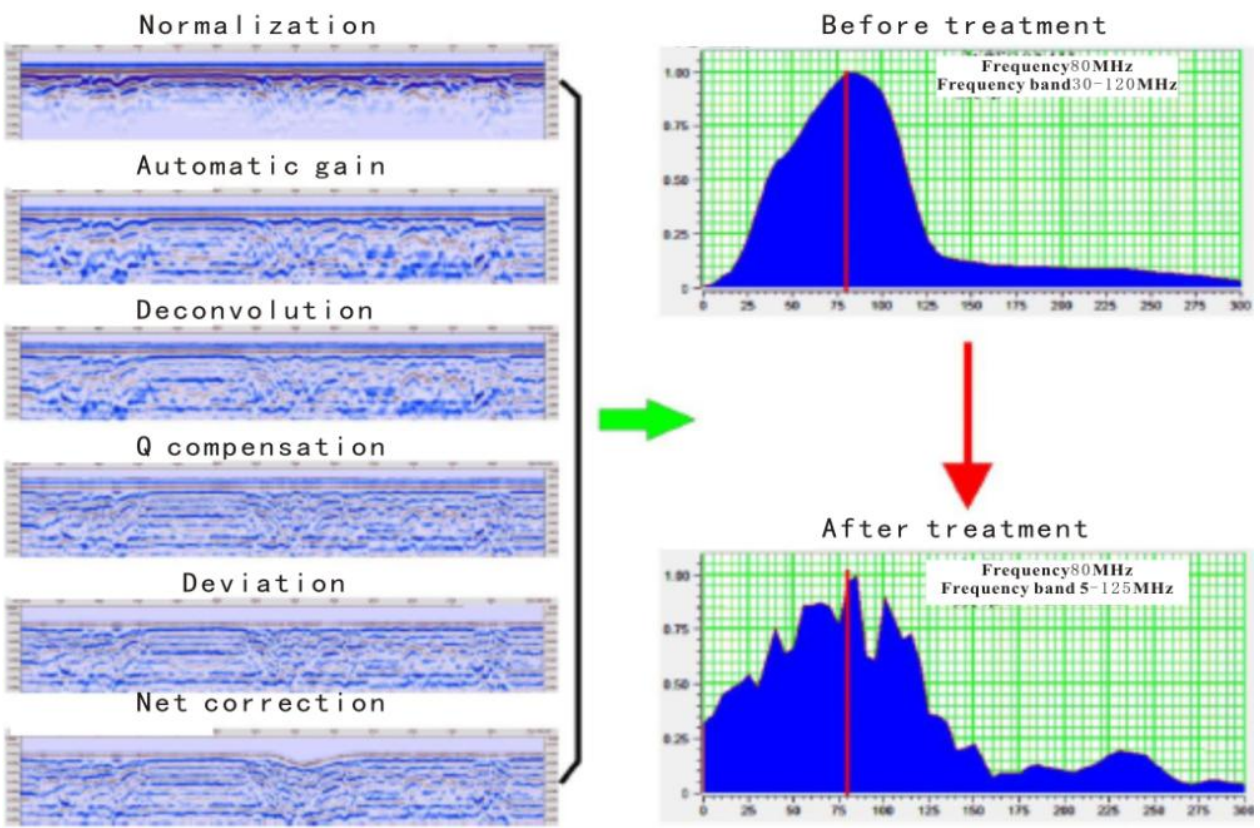

Fig. 2 GPR data processing flow

After processing of GPR profile data and the original data were compared, can be seen after processing of GPR data to improve the resolution, and repair the true shape of radar topographic profile concave interface, improve the fidelity, lay the foundation for the modern data deposition prototype model accurate imaging.

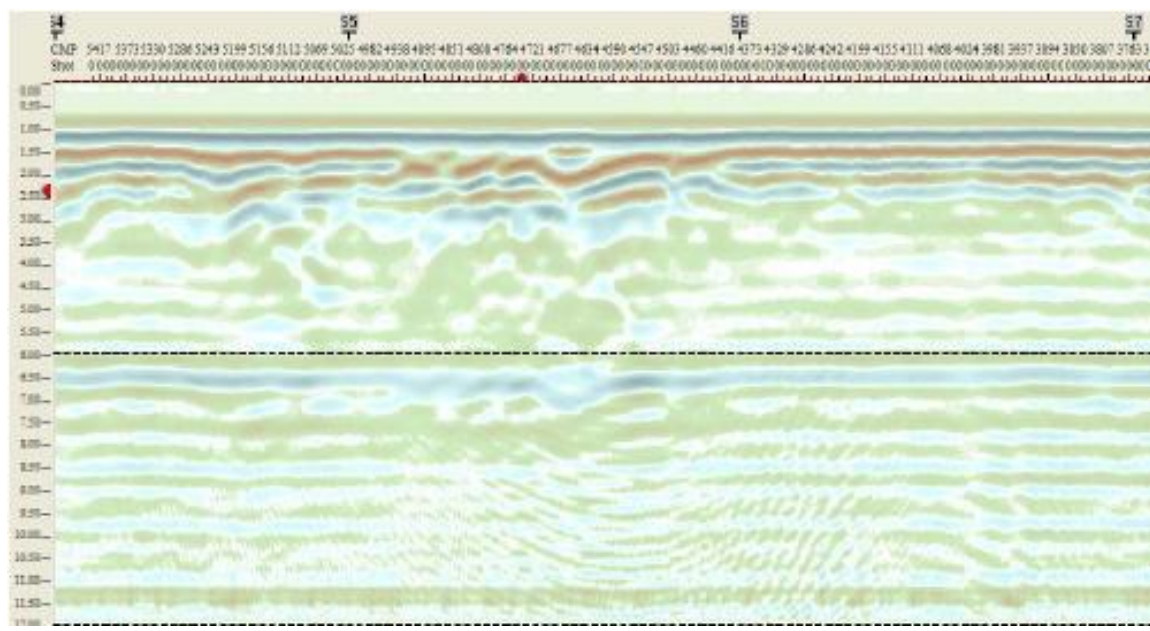

Fig. 3 original data of measured data of the target 1A1

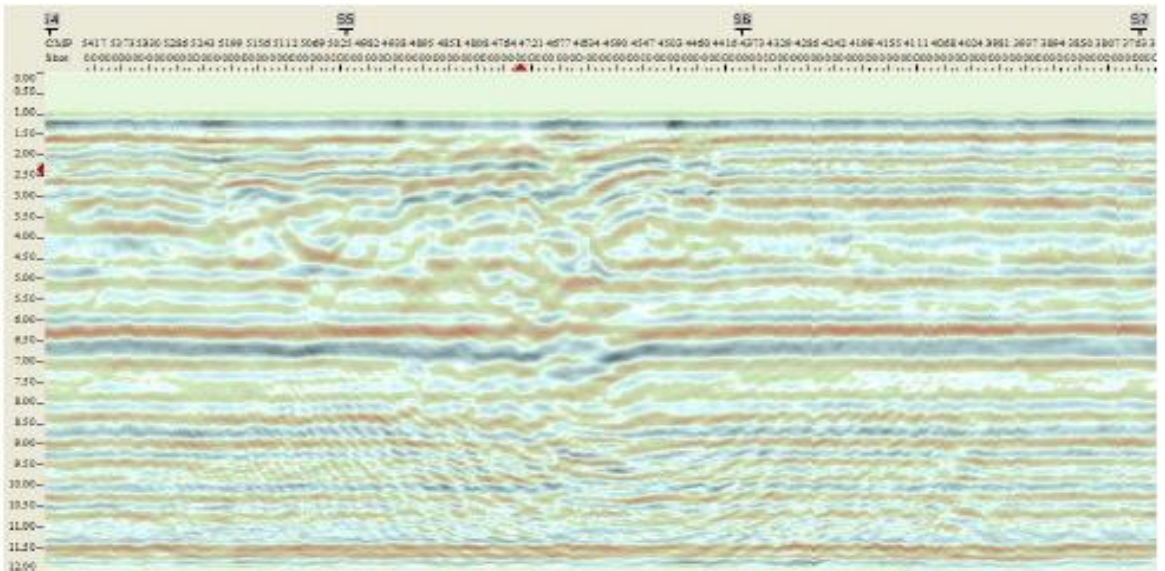

Fig. 4 Schematic diagram of the measured data of the target 1A1 


\section{Fine interpretation of ground penetrating radar profiles}

For the target 1 , the target body 2 of the 4 sections of the backbone of the structural characterization. The 1 body of the target body is composed of two points of dam overlap area. The meander belt radar data measuring complex analysis of composite point bar and internal lateral accretion body distribution pattern and evolution mechanism. The total line is 37 .

As shown in Figure 5, in the target body $1 \mathrm{~A} 8, \mathrm{C} 4$, respectively, through the cross-section of the abandoned river channel, abandoned channel 2, abandoned river channel 3, and cross over point dam, 1, 2, 3, 4 . From Figure 4-2, 4-3 can see the abandoned channel profile showed asymmetry in local curvature is larger, the smaller the abandoned channel height cutting high elevation of abandoned channel, abandoned channel is wide at the top, along the river channel boundary down please abandoned channel will gradually become larger point bar 4 is formed first, abandoned channel 2 cutting. After a time depth conversion can draw the elevation difference of about $0-8 \mathrm{~m}, 2$ abandoned channel 1 channel cutting, and elevation difference is about $1-2 \mathrm{~m}$. The abandoned channel width is around $30 \mathrm{~m}$, thawed off center, at about $4 \mathrm{~m}$ depth, lateral inclination of 10 layers. 4 degrees to $12-3$ degrees.

The 2 point dam of the target body is composed of the following three parts with different lateral direction. By measuring the dip angle and inclination of the lateral accretion of different parts, the development process, forming mechanism and spatial distribution of the target bar dam are clearly defined. As shown in Figure 6, the radar profile A14 and B6 intersect vertically, which are parallel to the direction of the lateral migration of the two secondary points of the dam at the same time? The abandoned channel width of about $30 \mathrm{~m}$, depth of 4-5m, the point bar developed inside the 6 side layer by measuring angle in 9-3 degrees to 13-1 degrees.

In the target area, a total of four field trough sections were collected, and the lithology and profile structure of the 4 probe sections were explained. The interpretation results are as follows: one is located in the $15 \mathrm{~m}$ main line, which is located on the A7 main line from the north to the south of the A7 line, $1 \mathrm{~km}$ away from the dam. The long axis of the probe is 33 degrees east of the north, with a length of $5 \mathrm{~m}$, a width of $1 \mathrm{~m}$ and a depth of 1-6m. There are two lateral mudstones in the trough, and the dip angle is slow. According to outcrop for channel filling, located near the Hulun Lake location may include distributaries channel. Also visible two sets of dark development, for the judgment of the meandering river point bar inner side layer. The upper part of the trench profile on the development of thick mudstone of abandoned channel mud, visible beneath thin side laminated mud.
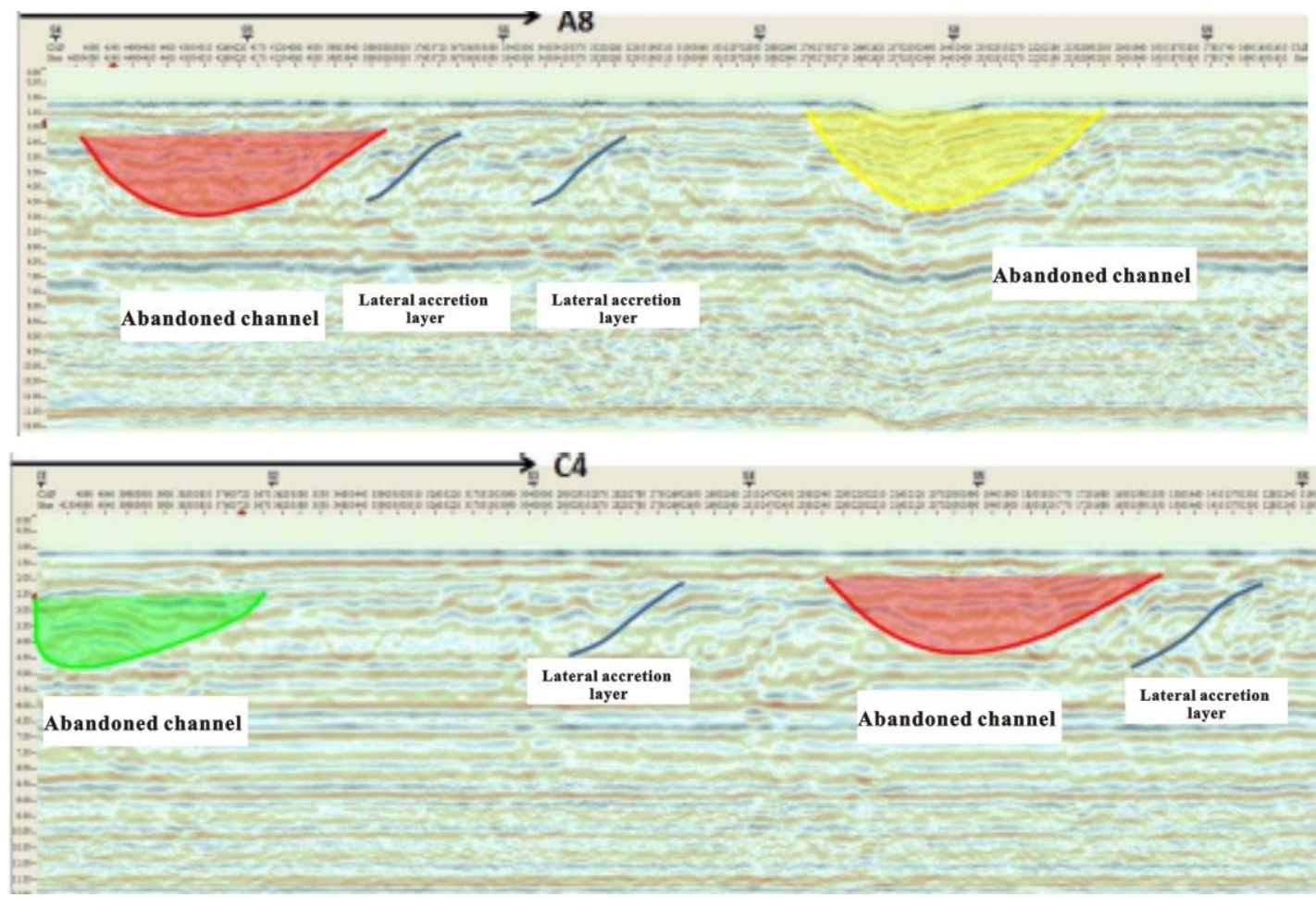

Figure $5 \mathrm{~A} 8$ and $\mathrm{C} 4$ anatomical configuration of the target 1 

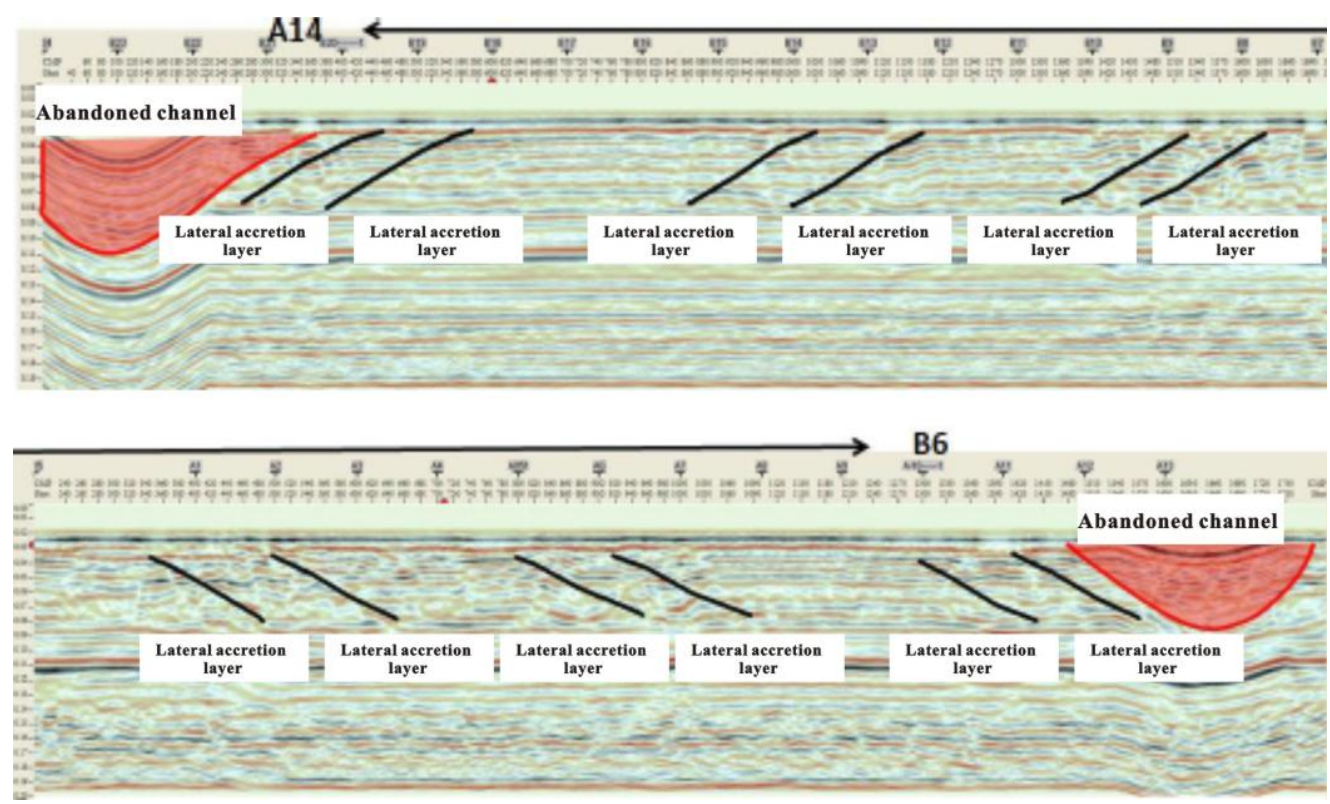

Figure 6 A14 and B6 anatomical configuration of the target 2

\section{Conclusion}

1) has abandoned channel asymmetric profile in local curvature is larger, the smaller the abandoned channel height cutting high elevation of abandoned channel, abandoned channel is wide at the top, along the river channel boundary down please abandoned channel will gradually become larger - point bar 4 is formed first, abandoned channel 2 cut, after time depth conversion can be the height difference of about $0-8 \mathrm{~m}, 2$ abandoned channel 1 channel cutting, elevation difference is about $1-2 \mathrm{~m}$. The abandoned channel width is around $30 \mathrm{~m}$, thawed off center, at about $4 \mathrm{~m}$ depth, lateral inclination of 10 layers. 4 degrees to 12-3 degrees.

2) Section A14 and B6 intersect vertically, and the lateral migration direction of the two secondary point dams is parallel to the complex single point dam. The abandoned channel width of about $30 \mathrm{~m}$, depth of $4-5 \mathrm{~m}$, the point bar developed inside the 6 side layer by measuring angle in 9-3 degrees to 13-1 degrees.

\section{Reference}

[1]. Chenglong Zhao. Case Study of Ground Penetrating Radar for Geological Prediction in Qiyueshan Tunnel[A]. Science and Engineering Research Center.Proceedings of 2015 2nd International Conference on Green Materials and Environmental Engineering (GMEE2015)[C].Science and Engineering Research Center:,2015:4.

[2]. Baojin GE,Lianjun WANG,Yi LI,Danfeng LI School of Civil Engineering,Beijing Jiaotong University,Beijing 100044. APPLICATION OF GROUND PENETRATING RADAR IN SUBGRADE DEFECT DETECTION ON DA-QIN HEAVY HAUL RAILWAY[A]. Beijing Jiaotong University,China、Beijing Key Laboratory of Track Engineering.New Technologies of Railway Engineering[C].Beijing Jiaotong University,China、Beijing Key Laboratory of Track Engineering:,2012:4.

[3]. Jidong L P Shijiazhuang University of Economics,Shijiazhuang,Hebei 050031,China. Urban underground drainage network investigation of ground penetrating radar[A]. Chinese Geophysical Society N National Natural Science Foundation of China 、 China University of Geosciences(CUG) 、 Chengdu University of Technology(CDUT).Near-Surface Geophysics and Geohazards--Proceedings of the 4 (th) International Conference on Environmental and Engineering Geophysics(Volume 2)[C].Chinese Geophysical Society、 National Natural Science Foundation of China、China University of Geosciences(CUG)、Chengdu University of Technology(CDUT):,2010:5.

[4]. Hongming Luo, Jiaying Wang, Peimin Zhu, Boxun Xiao Institute of Geophysics and Geomatics, China University of Geosciences, Wuhan, 430074, China Institute of Changjiang Engineering Geophysical Exploration, Wuhan, 430010, China. Study of Fourier finite-difference migration method in phased-array ground penetrating radar data[A]. Chinese Geophysical Society 、 China University of Geosciences.Goephysical Solutions for Environment and Engineering----Proceedings of the 2nd International Conference on Environmental and Engineering Geophysics(Volume 1)[C].Chinese Geophysical Society、China University of Geosciences:,2006:5.

[5]. Benyu Liu, Yili Hu, Yonghua Chen Department of Geophysics, Yunnan University, Kunming, China Kunming Southward Geotechnical Engineering Company, Kunming, China. Application of ground penetrating radar to tunnel inspection on compactness of lining[A]. Chinese Geophysical Society、China University of Geosciences.Goephysical Solutions for Environment and Engineering----Proceedings of the 2nd International Conference on Environmental and Engineering Geophysics(Volume 1)[C].Chinese Geophysical Society、China University of Geosciences:,2006:5. 